\title{
Higher serum uric acid levels and advanced age are associated with an increased prevalence of colorectal polyps
}

\author{
MINORU TOMIZAWA $^{1}$, FUMINOBU SHINOZAKI ${ }^{2}$, RUMIKO HASEGAWA $^{3}$, YOSHINORI SHIRAI ${ }^{3}$, \\ YASUFUMI MOTOYOSHI ${ }^{4}$, TAKAO SUGIYAMA ${ }^{5}$, SHIGENORI YAMAMOTO ${ }^{6}$ and NAOKI ISHIGE $^{7}$ \\ Departments of ${ }^{1}$ Gastroenterology, ${ }^{2}$ Radiology, ${ }^{3}$ Surgery, ${ }^{4}$ Neurology, ${ }^{5}$ Rheumatology, ${ }^{6}$ Pediatrics and \\ ${ }^{7}$ Neurosurgery, National Hospital Organization, Shimoshizu Hospital, Yotsukaido, Chiba 284-0003, Japan
}

Received May 6, 2015; Accepted June 16, 2015

DOI: $10.3892 /$ br.2015.487

\begin{abstract}
The present study retrospectively analyzed the laboratory data of patients who had undergone a colonoscopy between April 2011 and March 2014, with the aim of assessing whether these variables could be used to predict the presence of colorectal polyps (CP). A total of 1,471 patients were enrolled (731 men, $68.5 \pm 10.8$ years; 740 women, $66.7 \pm 10.8$ years). One-way analysis of variance was performed to analyze the association between the presence of $\mathrm{CP}$ and a range of laboratory variables. Logistic regression analysis was performed to establish a regression equation to predict the presence of CP. Receiver-operator characteristics analysis was applied to investigate the performance of the regression equation. Patients with $\mathrm{CP}$ were older than those without $\mathrm{CP}(\mathrm{P}<0.0001)$. Serum uric acid (UA) levels were higher in patients with $\mathrm{CP}$, compared to those without $\mathrm{CP}(\mathrm{P}=0.0007)$. To investigate the possibility that older age and higher UA levels could predict the presence of $\mathrm{CP}$, logistic regression analysis was performed $(\mathrm{P}=0.0008)$. The regression equation was as follows: $\ln (p / 1-p)=2.79015-0.01836 \times$ age $-0.28542 \times$ UA $(\mathrm{mg} / \mathrm{dl})$, where $p$ indicates the presence of CP. Receiver-operator characteristic analysis showed the area under the curve to be 0.62092 and the threshold value of $\mathrm{P}$ was 0.4370 . Sensitivity and specificity of the threshold value were 77.6 and $44.2 \%$, respectively. Advanced age and higher serum UA levels were associated with the presence of $\mathrm{CP}$. In conclusion, logistic regression analysis obtained a regression equation that predicted the presence of $\mathrm{CP}$ with a higher sensitivity, but poorer specificity, compared to fecal occult blood testing.
\end{abstract}

Correspondence to: Dr Minoru Tomizawa, Department of Gastroenterology, National Hospital Organization, Shimoshizu Hospital, 934-5 Shikawatashi Street, Yotsukaido, Chiba 284-0003, Japan

E-mail: nihminor-cib@umin.ac.jp

Key words: logistic regression analysis, likelihood analysis, receiver-operator characteristic analysis, blood urine nitrogen

\section{Introduction}

Colorectal cancer is frequently encountered in clinical practice (1). Long-term surveillance indicates that the majority of colorectal cancers arise from colorectal polyps (CP) (2). Polypectomy reduces the risk of fatality from colorectal cancer $(3,4)$. Screening using colonoscopy has also been shown to reduce the risk of colorectal cancer-related fatality $(5,6)$. However, colonoscopy is not available to all populations or patients, as it requires a skilled operator and therefore is associated with a significant cost (7). As colonoscopy is a limited resource, screening methods are required to select patients to undergo the procedure.

Fecal occult blood testing is widely available and reduces mortality from colorectal cancer (8). Fecal occult blood testing is useful for the diagnosis of advanced colorectal cancer (9); however, such an advanced cancer would not be amenable to polypectomy and therefore fecal occult blood testing is not suitable for the detection of patients with CP (10).

It is recommended that laboratory tests are completed prior to subjecting a patient to a colonoscopy, as this practice is associated with reduced rates of complications and lower costs (11). A correlation between laboratory test results and the presence of $\mathrm{CP}$, however, has not been reported.

The rate of $\mathrm{CP}$ detection is $37 \%$ for surveillance colonoscopy and 25\% for screening (12). Kim et al (13), in an analysis of risk factors for $\mathrm{CP}$, reported that CPs were identified in $47 \%$ of patients who underwent colonoscopy. The authors analyzed the association of $\mathrm{CP}$ with total cholesterol (T-Chol), triglycerides (TG), high-density lipoprotein (HDL) cholesterol and low-density lipoprotein (LDL) cholesterol levels. In a similar study, Huang et al (14) analyzed the association between CP and TG, HDL cholesterol, LDL cholesterol and glycated hemoglobin (HbA1c). These two studies concluded that the presence of CP is associated with metabolic risk factors. Therefore, it is expected that laboratory variables may be correlated with the presence of CP. The present study investigated whether laboratory variables are useful for predicting the presence of $\mathrm{CP}$.

\section{Materials and methods}

Patients. Patient records for the period between April 2011 and March 2014 were analyzed retrospectively. A total of 
Table I. Descriptive statistics for age and laboratory variables, according to colorectal polyp (CP) status.

\begin{tabular}{|c|c|c|c|c|c|c|}
\hline \multirow[b]{2}{*}{ Variables } & \multirow[b]{2}{*}{ Patients, no. } & \multicolumn{2}{|c|}{ Colonoscopy negative for $\mathrm{CP}$} & \multicolumn{2}{|c|}{ Colonoscopy positive for $\mathrm{CP}$} & \multirow[b]{2}{*}{ P-value } \\
\hline & & Patients, no. & Mean \pm SD & Patients, no. & Mean \pm SD & \\
\hline Age, years & 1,471 & 775 & $66.4 \pm 11.9$ & 696 & $68.9 \pm 9.4$ & $<0.0001$ \\
\hline $\mathrm{WBC}, 10^{2} / \mu 1$ & 698 & 381 & $6961 \pm 2087$ & 317 & $6134 \pm 1884$ & 0.2559 \\
\hline $\mathrm{Hb}, \mathrm{g} / \mathrm{dl}$ & 697 & 381 & $13.0 \pm 2.1$ & 316 & $13.1 \pm 2.1$ & 0.3069 \\
\hline $\mathrm{CRP}, \mathrm{mg} / \mathrm{dl}$ & 376 & 209 & $0.77 \pm 1.99$ & 167 & $0.88 \pm 3.45$ & 0.6958 \\
\hline Plt, $10^{4} / \mu 1$ & 690 & 378 & $21.9 \pm 7.1$ & 312 & $22.2 \pm 6.9$ & 0.5895 \\
\hline $\mathrm{TP}, \mathrm{g} / \mathrm{dl}$ & 452 & 254 & $6.9 \pm 0.8$ & 198 & $6.9 \pm 0.7$ & 0.4954 \\
\hline Alb, g/dl & 334 & 181 & $4.1 \pm 0.5$ & 153 & $4.0 \pm 0.6$ & 0.2336 \\
\hline T-Bil, mg/dl & 462 & 260 & $0.77 \pm 0.46$ & 202 & $0.74 \pm 0.32$ & 0.4288 \\
\hline ALP, IU/1 & 244 & 130 & $233.1 \pm 81.7$ & 114 & $229.0 \pm 84.5$ & 0.6964 \\
\hline AST, IU/1 & 634 & 335 & $25.1 \pm 25.3$ & 279 & $25.4 \pm 11.9$ & 0.8642 \\
\hline ALT, IU/1 & 668 & 366 & $22.6 \pm 28.0$ & 302 & $23.1 \pm 0.8$ & 0.7863 \\
\hline GGT, IU/1 & 279 & 147 & $56.3 \pm 274.7$ & 132 & $44.9 \pm 57.5$ & 0.6401 \\
\hline LDH, IU/1 & 363 & 192 & $201.3 \pm 60.7$ & 171 & $205.9 \pm 124.8$ & 0.6508 \\
\hline $\mathrm{UA}, \mathrm{mg} / \mathrm{dl}$ & 272 & 138 & $5.0 \pm 1.4$ & 134 & $5.5 \pm 1.4$ & 0.0007 \\
\hline BUN, mg/dl & 434 & 234 & $14.9 \pm 4.8$ & 200 & $16.5 \pm 14.5$ & 0.1109 \\
\hline $\mathrm{Cr}, \mathrm{mg} / \mathrm{dl}$ & 670 & 367 & $0.84 \pm 0.44$ & 303 & $0.86 \pm 0.25$ & 0.3734 \\
\hline T-Chol, mg/dl & 273 & 164 & $204.9 \pm 39.9$ & 109 & $196.4 \pm 33.6$ & 0.0703 \\
\hline $\mathrm{TG}, \mathrm{mg} / \mathrm{dl}$ & 253 & 117 & $124.7 \pm 81.9$ & 136 & $138.2 \pm 79.8$ & 0.1867 \\
\hline HDL, mg/dl & 192 & 103 & $61.3 \pm 17.6$ & 89 & $56.4 \pm 16.3$ & 0.0512 \\
\hline LDL, mg/dl & 264 & 129 & $118.4 \pm 29.7$ & 135 & $117.5 \pm 25.4$ & 0.7762 \\
\hline $\mathrm{BG}, \mathrm{mg} / \mathrm{dl}$ & 350 & 184 & $116.6 \pm 39.0$ & 166 & $122 \pm 46.8$ & 0.1892 \\
\hline $\mathrm{HbA} 1 \mathrm{c}, \%$ & 172 & 83 & $6.2 \pm 1.0$ & 89 & $6.2 \pm 1.1$ & 0.7721 \\
\hline $\mathrm{BMI}, \mathrm{kg} / \mathrm{m}^{2}$ & 252 & 124 & $22.5 \pm 3.9$ & 128 & $22.5 \pm 3.6$ & 0.8825 \\
\hline CEA, ng/ml & 183 & 99 & $12.0 \pm 63.3$ & 84 & $49.1 \pm 391.5$ & 0.3550 \\
\hline CA19-9, U/ml & 182 & 98 & $14.7 \pm 12.4$ & 84 & $38.8 \pm 221.7$ & 0.2836 \\
\hline
\end{tabular}

Number of patients refers to the total number subjected to each laboratory test. WBC, white blood cell count; Hb, hemoglobin; CRP, C-reactive protein; Plt, platelet; TP, total protein; Alb, albumin; T-Bil, total bilirubin; ALP, alkaline phosphatase; AST, aspartate aminotransferase; ALT, alanine aminotransferase; GGT, $\gamma$-glutamyl transpeptidase; LDH, lactate dehydrogenase; UA, uric acid; BUN, blood urea nitrogen; Cr, creatinine; T-Chol, total cholesterol; TG, triglyceride; HDL, high-density lipoprotein cholesterol; LDL, low-density lipoprotein cholesterol; BG, blood glucose; HbA1c, hemoglobin A1c; BMI, body mass index; CEA, carcinoembryonic antigen; CA19-9, carbohydrate antigen 19-9; SD, standard deviation.

1,520 patients underwent colonoscopy during this period. The majority of colorectal cancers arise from $\mathrm{CP}$, which progress via the adenoma-carcinoma sequence (15). In rare cases, de novo colorectal cancers occur (16) and it can sometimes be hard to distinguish between the adenoma-carcinoma sequence and de novo carcinogenesis. Patients with colorectal cancer $(n=49)$ were therefore excluded from the analysis, leaving 1,471 eligible patients; 731 men (mean age, $68.5 \pm 10.8$ years) and 740 women (mean age, $66.7 \pm 10.8$ years). The study was submitted to the institutional ethical committee at the National Hospital Organization, Shimoshizu Hospital (Yotsukaido, Chiba, Japan) and assigned as not a clinical trial, since it was performed as part of routine clinical practice. Patient anonymity was preserved.

Colonoscopy. Colonoscopy was performed for patients with abdominal symptoms, anemia or a positive fecal occult blood test result. Colonoscopy was also performed for screening. The colonoscopes used were CF-Q260 and PCF-Q260AI (Olympus, Tokyo, Japan). The withdrawal time of colonoscopy ranged from 10 to $30 \mathrm{~min}$. The diameter of the smallest polyps detected was $2 \mathrm{~mm}$.
Laboratory variables. The variables analyzed as potential predictors of CP included white blood cell count, hemoglobin, C-reactive protein, platelet count, total protein, albumin level, total bilirubin level, alkaline phosphatase, aspartate aminotransferase, alanine aminotransferase, $\gamma$-glutamyl transpeptidase, lactate dehydrogenase, uric acid (UA), blood urea nitrogen, creatinine, T-Chol, TG, HDL cholesterol, LDL cholesterol, blood glucose, HbAlc, body mass index, carcinoembryonic antigen and carbohydrate antigen 19-9. Blood was collected in the fasting period from the majority of patients.

Statistical analysis. One-way analysis of variance (ANOVA) was performed to analyze the association between each variable and the presence of CP. The mean UA level was analyzed, according to age group, with one-way ANOVA. A $\chi^{2}$ test was performed to analyze the association between age group and $\mathrm{CP}$ prevalence. The $\chi^{2}$ test was also applied to analyze the correlation between the percentage of patients with UA $>7 \mathrm{mg} / \mathrm{dl}$. Logistic regression analysis was performed to establish a regression equation that could predict the presence of CP. Receiver-operator characteristic analysis was applied to investigate the performance of the regression equation. $\mathrm{P}<0.05$ 
Table II. Association between age and prevalence of colorectal polyps (CP).

\begin{tabular}{lcccccc}
\hline & & \multicolumn{2}{c}{$\mathrm{CP}(-)$} & & \multicolumn{2}{c}{$\mathrm{CP}(+)$} \\
\cline { 7 - 8 } $\begin{array}{l}\text { Age group, } \\
\text { years }\end{array}$ & Patients, no. & $\%$ & $\chi^{2}$ test & & $\%$ & $\chi^{2}$ test \\
\hline 30 & 31 & 83.9 & 5.7225 & & 16.1 & 6.3720 \\
40 & 92 & 66.3 & 3.2389 & & 33.7 & 3.6065 \\
50 & 120 & 60.0 & 1.2187 & & 40.0 & 1.3570 \\
60 & 497 & 51.3 & 0.1790 & & 48.7 & 0.1993 \\
70 & 577 & 49.1 & 1.4498 & & 50.9 & 1.6144 \\
80 & 146 & 49.3 & 0.3148 & 50.7 & 0.3505 \\
\hline
\end{tabular}

$\chi^{2}$ test was performed to clarify the association between age and the presence of colorectal polyps. $\mathrm{P}=0.0001$. $\mathrm{CP}(-)$, patients without colorectal polyps; $\mathrm{CP}(+)$, patients with colorectal polyps.

was considered to indicate a statistically significant difference. JMP 10.0.2 (SAS Institute Inc., Cary, NC, USA) was used for statistical analysis.

\section{Results}

Associations between laboratory variables and presence of $C P$. The associations between each laboratory test variable and the presence of CP is presented in Table I. Not all the patients were subjected to each laboratory test. Patients with CP were of a more advanced age compared to those without $\mathrm{CP}(\mathrm{P}<0.0001)$. Serum UA levels were higher in patients with $\mathrm{CP}$, compared with those without $\mathrm{CP}(\mathrm{P}=0.0007)$. These results suggest that age and UA level were strongly associated with the presence of $\mathrm{CP}$; these variables were chosen for further analysis.

Association between age and presence of $C P$. The association between the percentage of patients with $\mathrm{CP}$ and age is illustrated in Fig. 1; the presence of $\mathrm{CP}$ increased with age. This association was statistically significant $(\mathrm{P}=0.0001)$ (Table II). The number of patients in their 20s and 90s were 3 and 5, respectively. As these ages were significantly fewer in number compared with the other age groups, these patients were omitted from further analysis.

Serum UA level and the presence of $C P$. The serum UA level was correlated with the presence of $\mathrm{CP}$; however, there was a possibility that this association was confounded by an association of UA level with age. Fig. 2 indicates that there was no association between a higher UA level and age.

The $\chi^{2}$ test confirmed an absence of correlation between UA level and age $(\mathrm{P}=0.6279)$.

The above data indicated that the presence of $\mathrm{CP}$ correlated with aging and UA. To investigate the possibility that age and UA level could predict the presence of $\mathrm{CP}$, logistic regression analysis was performed $(\mathrm{P}=0.0008)$ (Table III). The regression equation was as follows: $\ln (p / 1-p)=2.79015-0.01836 \mathrm{x}$ age $-0.28542 \times$ UA level $(\mathrm{mg} / \mathrm{dl})$, where $p$ represents the presence of CP.

The likelihood ratio $\chi^{2}$ test showed a P-value for age and UA level of 0.1083 and 0.0011 , respectively, indicating a strong correlation between UA level and the presence of CP.
Table III. Logistic regression analysis for the association between age and serum uric acid level.

\begin{tabular}{lrcc}
\hline Characteristics & $\chi^{2}$ test & Odds & Likelihood test (P-value) \\
\hline Age & 2.53 & 0.981808 & 0.1083 \\
Uric acid & 10.03 & 0.751701 & 0.0011 \\
\hline
\end{tabular}

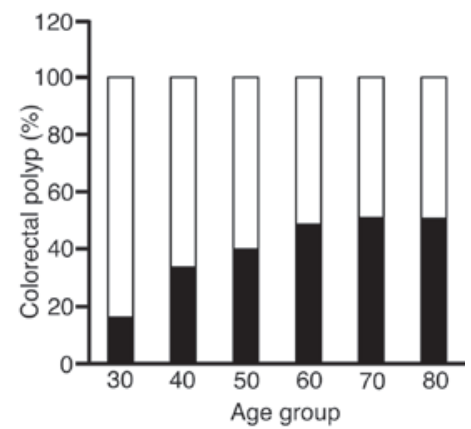

Figure 1. Prevalence of colorectal polyps according to age. White bar, patients without colorectal polyps; black bar, patients with colorectal polyps.

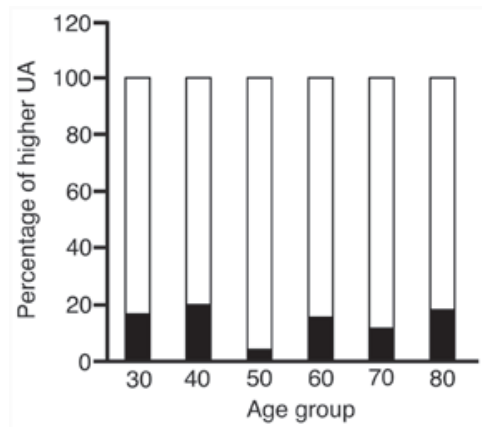

Figure 2. Prevalence of patients with a high serum uric acid (UA) level $(>7 \mathrm{mg} / \mathrm{dl}$ ) according to age. Patients in their $20 \mathrm{~s}$ and $90 \mathrm{~s}$ were omitted as there were only 3 and 5 patients in the groups, respectively. White bar, patients with UA level $<7 \mathrm{mg} / \mathrm{dl}$; black bar, patients with UA $>7 \mathrm{mg} / \mathrm{dl}$.

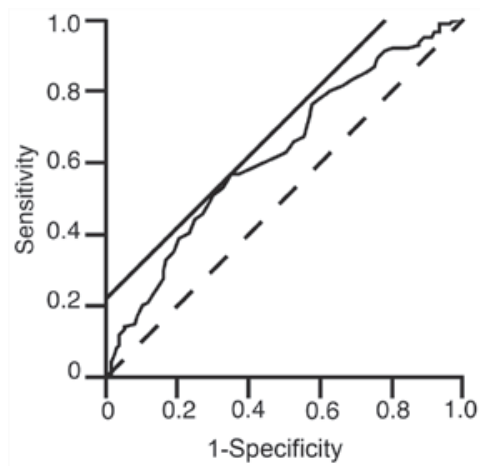

Figure 3. Receiver-operator characteristic analysis of the regression equation to predict the presence of colorectal polyps. Solid straight line represents a line with a slope of $45^{\circ}$, used by the software to calculate threshold; broken line indicates the reference line.

Receiver-operator characteristic analysis. To investigate how well the regression equation predicted the presence of $\mathrm{CP}$, receiver-operator characteristic analysis was applied (Fig. 3). 
The area under the curve was 0.62092 . The threshold value of $\mathrm{P}$ was 0.4370 , and the sensitivity and specificity of the threshold value were 77.6 and $44.2 \%$, respectively.

\section{Discussion}

Previous investigations into the correlation between laboratory test results and the presence of $\mathrm{CP}$ have focused on components of metabolic syndrome (17), and the literature regarding the association between UA level and the presence of $\mathrm{CP}$ is limited. Orannapalai et al (18) analyzed the correlation between laboratory test results and the presence of CP. Patients were divided into 2 groups, based on UA level; $>7$ and $\leq 7 \mathrm{mg} / \mathrm{dl}$. The presence of CP was higher in the group with a UA level of $>7 \mathrm{mg} / \mathrm{dl}$. In the present study, the average level of UA was higher in patients with CP compared with patients without $\mathrm{CP}$, which is consistent with the results of the previous report. The underlying reason for this association is unknown. Notably, Karaman et al (19) found that the average UA level was higher in patients with neoplastic CP, as compared to those with non-neoplastic CP. Patients with a higher UA level are also prone to cancer of the colon, liver and lung (20). These results suggest that a raised serum UA level may be involved in tumorigenesis (21).

There is limited information available on the $\mathrm{CP}$ predictors. Eisner et al (22) performed urinary metabolomics in search of such a predictor and reported that nicotinate and nicotinamide metabolites and the degradation of ketone bodies are associated with the presence of CP. They proposed a tool involving the use of urinary metabolomics to select patients at risk of $\mathrm{CP}$, who would undergo further investigation with colonoscopy. The performance of this tool is more efficient than that of fecal occult blood testing. In the present study, age and UA level were associated with the presence of CP. It has previously been reported that advanced age is associated with the presence of CP (23). UA levels are also higher in patients with $\mathrm{CP}$, as discussed above. The present data are therefore consistent with previous reports. Fecal occult blood testing is intended to select patients with colorectal cancer, rather than pre-cancerous CP (24). Eisner et al (22) analyzed fecal occult blood testing as a tool for the detection of CP. Fecal occult blood testing has been shown to have a sensitivity of 2.6-15.1\% and a specificity of $94.5-99.4 \%$. In terms of the detection of $\mathrm{CP}$ using UA level, the present regression equation showed a greater sensitivity, but a poorer specificity.

In conclusion, advanced age and higher serum UA levels are associated with the presence of CP. Logistic regression analysis obtained a regression equation with a greater sensitivity and poorer specificity for the detection of $\mathrm{CP}$, compared with fecal occult blood testing.

\section{References}

1. Brenner H, Kloor M and Pox CP: Colorectal cancer. Lancet 383: 1490-1502, 2014

2. Stoian M, State N, Rusu E, Stoica V, Gavril RS, Gherasim A and Radulian G: Malignancy and mortality of colorectal polyps. Rev Med Chir Soc Med Nat Iasi 118: 399-406, 2014.

3. Zauber AG, Winawer SJ, O'Brien MJ, Lansdorp-Vogelaar I, van Ballegooijen M, Hankey BF, Shi W, Bond JH, Schapiro M, Panish JF, et al: Colonoscopic polypectomy and long-term prevention of colorectal-cancer deaths. N Engl J Med 366: 687-696, 2012.
4. Anderloni A, Jovani M, Hassan C and Repici A: Advances, problems and complications of polypectomy. Clin Exp Gastroenterol 7: 285-296, 2014.

5. Manser CN, Bachmann LM, Brunner J, Hunold F, Bauerfeind P and Marbet UA: Colonoscopy screening markedly reduces the occurrence of colon carcinomas and carcinoma-related death: A closed cohort study. Gastrointest Endosc 76: 110-117, 2012.

6. Rosa I, Fidalgo P, Soares J, Vinga S, Oliveira C, Silva JP, Ferro SM, Chaves P, Oliveira AG and Leitão CN: Adenoma incidence decreases under the effect of polypectomy. World J Gastroenterol 18: 1243-1248, 2012.

7. Wallace MB and Kiesslich R: Advances in endoscopic imaging of colorectal neoplasia. Gastroenterology 138: 2140-2150, 2010.

8. Shaukat A, Mongin SJ, Geisser MS, Lederle FA, Bond JH, Mandel JS and Church TR: Long-term mortality after screening for colorectal cancer. N Engl J Med 369: 1106-1114, 2013.

9. Viana Freitas BR, Kibune Nagasako C, Pavan CR, Silva Lorena SL, Guerrazzi F, Saddy Rodrigues Coy C, Ayrizono ML and Mesquita MA: Immunochemical fecal occult blood test for detection of advanced colonic adenomas and colorectal cancer: Comparison with colonoscopy results. Gastroenterol Res Pract 2013: 384561, 2013.

10. Bretagne JF, Manfredi S, Piette C, Hamonic S, Durand G and Riou F: Yield of high-grade dysplasia based on polyp size detected at colonoscopy: A series of 2295 examinations following a positive fecal occult blood test in a population-based study. Dis Colon Rectum 53: 339-345, 2010.

11. Sonnenberg A: Test sequence in the management of gastrointestinal bleeding. Endoscopy 44: 43-47, 2012.

12. Anderson JC, Butterly LF, Goodrich M, Robinson CM and Weiss JE: Differences in detection rates of adenomas and serrated polyps in screening versus surveillance colonoscopies, based on the new hampshire colonoscopy registry. Clin Gastroenterol Hepatol 11: 1308-1312, 2013.

13. Kim YJ, Lee KJ, Park SY, Han JH, Kwon KY and Kim JH: Association between Dyslipidemia and the Prevalence of Colon Polyps Based on a Health Evaluation of Subjects at a Hospital. Korean J Fam Med 35: 143-151, 2014.

14. Huang HE, Yang YC, Wu JS, Wang RH, Lu FH and Chang CJ: The relationship between different glycemic statuses and colon polyps in a Taiwanese population. J Gastroenterol 49: 1145-1151, 2014.

15. Al-Sohaily S, Biankin A, Leong R, Kohonen-Corish M and Warusavitarne J: Molecular pathways in colorectal cancer. J Gastroenterol Hepatol 27: 1423-1431, 2012.

16. Tanaka T: Colorectal carcinogenesis: Review of human and experimental animal studies. J Carcinog 8: 5, 2009.

17. Kim BC, Shin A, Hong CW, Sohn DK, Han KS, Ryu KH, Park BJ, Nam JH, Park JW, Chang HJ, et al: Association of colorectal adenoma with components of metabolic syndrome. Cancer Causes Control 23: 727-735, 2012.

18. Orannapalai N, Attawettayanon W, Kanngern S, Boonpipattanapong $\mathrm{T}$ and Sangkhathat S: Predicting the occurrence of cancer-associated colorectal polyp using a metabolic risk score. Mol Clin Oncol 2: 124-128, 2014.

19. Karaman H, Karaman A, Erden A, Poyrazoglu OK, Karakukcu C and Tasdemir A: Relationship between colonic polyp type and the neutrophil/lymphocyte ratio as a biomarker. Asian Pac J Cancer Prev 14: 3159-3161, 2013.

20. Boffetta P, Nordenvall C, Nyrén O and Ye W: A prospective study of gout and cancer. Eur J Cancer Prev 18: 127-132, 2009.

21. Wilson FP and Berns JS: Tumor lysis syndrome: New challenges and recent advances. Adv Chronic Kidney Dis 21: 18-26, 2014.

22. Eisner R, Greiner R, Tso V, Wang H and Fedorak RN: A machine-learned predictor of colonic polyps based on urinary metabolomics. Biomed Res Int 2013: 303982, 2013.

23. Clipp EC, Carver EH, Pollak KI, Puleo E, Emmons KM, Onken J, Farraye FA and McBride CM: Age-related vulnerabilities of older adults with colon adenomas: Evidence from Project Prevent. Cancer 100: 1085-1094, 2004.

24. Launois R, Le Moine JG, Uzzan B, Fiestas Navarrete LI and Benamouzig R: Systematic review and bivariate/HSROC random-effectmeta-analysis of immunochemical and guaiac-based fecal occult blood tests for colorectal cancer screening. Eur J Gastroenterol Hepatol 26: 978-989, 2014. 